
\title{
28 Research Square \\ Photocatalytic Degradation of Norfloxacin By Magnetic Molecularly Imprinted Polymers: Influencing Factors And Mechanisms
}

\section{Lei Fang}

Zhejiang University

Kaijie Tang

Zhejiang University

Dong Wei

Zhejiang University

Yan Zhang

Zhejiang University

Yongchao Zhou ( $\nabla$ zhoutang@zju.edu.cn )

Zhejiang University https://orcid.org/0000-0002-5524-4016

\section{Research Article}

Keywords: Magnetic molecularly imprinted polymers, Norfloxacin, Photocatalysis, Influencing factors, Insite regeneration, Applicability evaluation

Posted Date: May 25th, 2021

DOI: https://doi.org/10.21203/rs.3.rs-392691/v1

License: (c) (1) This work is licensed under a Creative Commons Attribution 4.0 International License.

Read Full License

Version of Record: A version of this preprint was published at Environmental Technology on November 5th, 2021. See the published version at https://doi.org/10.1080/09593330.2021.2003442. 


\section{Abstract}

Novel magnetic molecularly imprinted polymers (MMIP) were prepared for selective removal of norfloxacin from ambient water by effectively utilizing photocatalytic degradation and magnetic separation techniques. The imprinted materials with titanium layer and multihole surface showed excellent photocatalytic property. In this paper, the kinetics of photocatalytic degradation of norfloxacin by MMIP was explored, and the influences of environmental factors, including solution $\mathrm{pH}$, humic acid, common ions and water media on photocatalytic performance of the materials were elucidated. The results showed that MMIP had good adaptability and could degrade norfloxacin within 60 min, but the degradation rate constant decreased by $40.3 \%$ and $66.4 \%$ in tap water and surface water, respectively. According to the intermediates, the possible degradation pathways of norfloxacin were analyzed, speculating that norfloxacin might be degraded into small molecules after de-piperazine ring, de-carboxyl group and de-fluorine. Moreover, the mineralization ratio of norfloxacin could reach $84.2 \%$ after ultraviolet irradiation for $150 \mathrm{~min}$. In the study of photocatalytic in-situ regeneration and recovery performance of MMIP, the total removal efficiency of norfloxacin was still $99.0 \%$ after seven cycles of adsorptiondegradation tests. And the low cobalt release of MMIP by molecular imprinting technology enhanced the security of the materials.

\section{Introduction}

In recent years, the production and consumption of antibiotics have been increased all over the world, while their potential adverse effects on ecology and human health have attracted more attention. A literature research showed that 110 antibiotics have been detected in China's environment, most of these were in aquatic environments (Huang et al. 2020). Through cluster analysis, seven dominant antibiotics, including norfloxacin, can be discovered in almost all environmental compartments with concentrations up to several micrograms per liter. In some bodies of water in European countries, such as wastewater, surface water, groundwater and drinking water, quinolones were the most frequently detected antibiotics (Carvalho and Santos 2016). These phenomena indicated that quinolone antibiotics were more likely to accumulate in the environment and had strong persistence (Xi et al. 2019). Norfloxacin is a kind of fluoroquinolones drug with stable chemical structure and poor biodegradability. However, traditional sewage treatment technologies are not enough to remove norfloxacin effectively because of its special properties such as low concentration and high bio-toxicity (de Souza Santos et al. 2014). The main migration pathways of norfloxacin are the discharge of livestock wastewater, effluent and sludge into surface water, groundwater and soil, respectively (Huang et al. 2020). Therefore, it is urgent to develop the effective technology for norfloxacin removal from drinking water and wastewater.

Although antibiotics such as norfloxacin are ubiquitous in the environment, their concentration is lower than that of other conventional organics. Molecularly imprinted polymers (MIP) can selectively adsorb trace pollutants in water environment (BelBruno 2019), which is extremely beneficial for the removal of norfloxacin with low concentration and high toxicity. Tan et al. (2013) synthesized ofloxacin imprinted polymers on the surface of mesoporous carbon nanoparticles to prove the feasibility of MIP to remove 
fluoroquinolone antibiotics from seawater. MIP had high selectivity and affinity for template molecules, for they contained a large number of "tailor-made" binding sites (Shen et al. 2012). Similarly, fluoroquinolone imprinted polymers had also been developed for the extraction and detection of relevant antibiotics in actual water samples (Barahona et al. 2019). However, such imprinted materials cannot degrade the adsorbed pollutants, resulting in poor regeneration performance of the polymers, while elution may well cause environmental pollution.

Photocatalysis reaction can effectively degrade organic pollutants (Dong et al. 2015). The use of photocatalysis to remove pollutants adsorbed on MIP is a new technology (Sajini et al. 2019). The degradation of the target adsorbent on the MIP surface allows the materials to be reused. Due to the selective adsorption of MIP, they exhibit better photocatalytic activity to the target material. Some representative estrogenic chemicals could be selectively and rapidly removed from secondary effluents of municipal wastewater treatment plants using photocatalyst prepared by surface molecularly imprinted $\mathrm{TiO}_{2}$ nanotubes (Zhang et al. 2013). Compared with organic imprinting, the synthetic method of inorganic imprinting nano $\mathrm{TiO}_{2}$ layer on microspheres was demonstrated higher catalytic efficiency for the degradation of bisphenol A under ultraviolet light (Ye et al. 2019). A TiO ${ }_{2}$-based imprinted material showed outstanding photocatalytic in-situ regeneration performance, after eleven regeneration cycles, the adsorption and degradation removal efficiency of MIP to norfloxacin did not decrease significantly (Wei et al. 2018). In addition, some imprinted polymers that can degrade template molecules in visible light had also been prepared (Du et al. 2020), but their degradation efficiency was not as outstanding as that under ultraviolet light. However, the imprinted photocatalytic materials listed above are difficult to separate from the solution. The material must be centrifuged from the decontaminated water to achieve reuse, whereas the recovery ratio is low.

Nowadays, there have been many researches to fix powdered materials on various substrates (Shan et al. 2010). For photocatalytic materials, the most common is the glass substrate (Pestana et al. 2015). However, material immobilization would reduce the exposure area of the catalyst, and the loaded materials might be lost due to the continuous scouring and friction of the water flow (Jiang et al. 2019). Magnetic separation technology is different from immobilization technology, which has the characteristics of environmental protection and high efficiency. The synthesized material has its own magnetism, which can separate from the solution by applying an external magnetic field (Wang et al. 2015). The magnetic molecularly imprinted composite material prepared by cross-linking chitosan and $\mathrm{y}^{-}$ $\mathrm{Fe}_{2} \mathrm{O}_{3}$ particles showed effective norfloxacin adsorption performance when mixing with other organic matter in the effluent of the actual sewage treatment plant (Wu et al. 2016). Heterojunction of magnetic core $\mathrm{CuFe}_{2} \mathrm{O}_{4}$ and photocatalyst g- $\mathrm{C}_{3} \mathrm{~N}_{4}$ improved the separation efficiency of photoinduced electron-hole pairs (Yao et al. 2015). More experiments showed the degradation mechanism of magnetic nanophotocatalyst was similar to that of single photocatalyst (Kumar et al. 2019). It can be seen that magnetic separation technology combined with molecular imprinting and photocatalysis technology has good development prospects. 
In this paper, we synthesized magnetic molecularly imprinted polymers with specific recognition ability for norfloxacin and photocatalytic in-situ regeneration. Magnetic cores, $\mathrm{TiO}_{2}$ coating and surface molecular imprinting modification were adopted to realize the photocatalytic regeneration and magnetic separation recovery. Based on previous research about the adsorption performance, we have reported the characterization and selective adsorption properties of the materials towards norfloxacin (Fang et al. 2021). However, the degradation efficiency of target pollutants and the regeneration of MMIP still need to be investigated. Here, the kinetics of photocatalytic degradation was studied, and the influences of different environmental media factors on the photocatalytic degradation performance of the material were systematically explored. Besides, the products, pathways and mineralization of photocatalytic reactions were further analyzed to evaluate the security and sustainability of the materials.

\section{Materials And Methods}

\subsection{Chemicals and materials}

Norfloxacin $\left(\mathrm{C}_{16} \mathrm{H}_{18} \mathrm{FN}_{3} \mathrm{O}_{3}, 98.0 \%\right)$, ferric chloride $\left(\mathrm{FeCl}_{3}, 99.0 \%\right)$, cobalt chloride hexahydrate $\left(\mathrm{CoCl}_{2} \cdot 6 \mathrm{H}_{2} \mathrm{O}\right.$, AR) and tetrabutyl titanate $\left(\mathrm{Ti}\left(\mathrm{OC}_{4} \mathrm{H}_{9}\right)_{4}, 99.0 \%\right)$ were obtained from Aladdin Industrial Corporation (Shanghai, China). Methanol, acetonitrile and phosphoric acid were all of HPLC grade, purchased from Sigma-Aldrich (USA). Ethylene glycol, polyethylene glycol, sodium acetate, ammonium hexafluorotitanate, boric acid, hydrochloric acid, sodium hydrate, sodium chloride, sodium sulfate, sodium nitrate and other analytical reagents were uniformly purchased from Sinopharm Chemical Reagent Company (Shanghai, China). A 10 W ultraviolet lamp used was from Heraeus Holding (Hanau, Germany). All reagents were used directly without further purification.

\subsection{Preparation and characterization of MMIP}

The synthesis of MMIP consisted of three steps. Firstly, $50 \mathrm{mmol} \mathrm{FeCl}$ and $25 \mathrm{mmol} \mathrm{CoCl} \cdot 6 \mathrm{H}_{2} \mathrm{O}$ were dissolved in $400 \mathrm{ml}$ ethylene glycol. Then $36 \mathrm{~g}$ sodium acetate and $10 \mathrm{~g}$ polyethylene glycol were added into the mixture. The suspension was transferred into Teflon-lined reaction kettle, and heated at $200{ }^{\circ} \mathrm{C}$ for $8 \mathrm{~h}$ to get $\mathrm{CoFe}_{2} \mathrm{O}_{4}$. Secondly, $2 \mathrm{~g} \mathrm{CoFe} \mathrm{O}_{4}$ was added into a mixture solution containing anhydrous ethanol and tetrabutyl titanate. The suspension was heated at $150{ }^{\circ} \mathrm{C}$ for $10 \mathrm{~h}$ in autoclave to obtain $\mathrm{CoFe}_{2} \mathrm{O}_{4} @ \mathrm{TiO}_{2}$. At last, 200 mg CoFe $\mathrm{O}_{4} @ \mathrm{TTiO}_{2}$ nanoparticles, 20 mg norfloxacin, $3.96 \mathrm{~g}$ ammonium hexafluorotitanate and $2.60 \mathrm{~g}$ boric acid were dissolved in deionized water, stirred for $2 \mathrm{~h}$ and then natural deposited. The molecularly imprinted particles were calcined under $350^{\circ} \mathrm{C}$ to remove templates.

The morphological characterization and surface elements of the materials were carried out using scanning electron microscope with an X-ray energy spectrometer (GeminiSEM 300, Zeiss, Germany).

\subsection{Photocatalytic degradation experiments}

After the reaction reached the adsorption equilibrium, the magnetic photocatalytic material was regenerated in-situ by ultraviolet photocatalytic degradation. $40 \mathrm{mg}$ material was put into $100 \mathrm{~mL}$ 
norfloxacin solution with a concentration of $2 \mathrm{mg} \mathrm{L}^{-1}$. After stirring $60 \mathrm{~min}$ at $25^{\circ} \mathrm{C}$, the reaction vessel was illuminated by a $254 \mathrm{~nm}$ ultraviolet lamp with power of $10 \mathrm{~W}$. The light source was turned on in advance and preheated for 10 min which intensity can be stabilized at about $927 \mu \mathrm{W} \mathrm{cm}^{-2}$. Samples were then taken out at regular intervals and filtered by a $0.45 \mu \mathrm{m}$ filter. Photocatalytic kinetics of MMIP was investigated over various initial concentrations ranging from $1 \mathrm{mg} \mathrm{L}^{-1}$ to $25 \mathrm{mg} \mathrm{L}^{-1}$. The environmental factors including $\mathrm{pH}$ values, concentrations of humic acid, different ions and water media were selected to research the photocatalytic performance of the material. The degradation efficiency was defined as:

Efficiency $(\%)=\frac{c_{0}-c_{1}}{c_{0}}$

Where $c_{0}\left(\mathrm{mg} \mathrm{L}^{-1}\right)$ and $c_{1}\left(\mathrm{mg} \mathrm{L}^{-1}\right)$ were the concentration of adsorption equilibrium and after photodegradation, respectively.

\subsection{Analytical methods}

The concentrations of norfloxacin were measured by high performance liquid chromatography (1200 Series, Agilent, USA) equipped with a XDB C18 column (4.6 mm×150 mm, $5 \mu \mathrm{m})$ and a fluorescence detector which excitation and emission wavelength were $280 \mathrm{~nm}$ and $450 \mathrm{~nm}$, respectively. The mobile phase was consisted of acetonitrile and $0.1 \mathrm{wt} \%$ phosphoric acid water solution at the volume ratio of

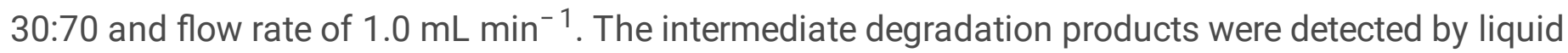
chromatography-mass spectrometry (6460 Triple Quad, Agilent, USA). The samples were extracted on solid phase extraction column ( $3 \mathrm{~mL} / 60 \mathrm{mg}$, Oasis HLB, Waters) and concentrated by nitrogen blowing. The liquid chromatography separation was carried out on Agilent Zorbax SB C18 column $(2.1 \mathrm{~mm} \times 150$ $\mathrm{mm}, 3.5 \mu \mathrm{m}$ ) and gradient elution was performed with acetonitrile and $0.25 \mathrm{wt} \%$ formic acid at a flow rate of $0.20 \mathrm{~mL} \mathrm{~min}{ }^{-1}$. Mass spectrometry analysis was adopted using an electrospray ionization source in positive mode and scanning range of $\mathrm{m} / \mathrm{z}$ was $100 \sim 1000 \mathrm{amu}$. The removal efficiency of total organic carbon (TOC) was adopted to characterize the mineralization of norfloxacin. Samples for the detection of TOC were measured through combustion catalytic oxidation at $680^{\circ} \mathrm{C}$ by using total organic carbon analyzer (TOC-VCPH, Shimadzu, Japan). In addition, the accurate concentration of cobalt was determined by inductively coupled plasma mass spectrometer (NexION 300Q, PerkinElmer, the United States).

\section{Results And Discussion}

\subsection{Characterization of MMIP}

The morphology of MMIP was confirmed by SEM image showing in Fig. 1a. It can be noted that there were a lot of nanoparticles on the surface of MMIP, which were presumed to be the generated imprinted layer and partially exposed $\mathrm{TiO}_{2}$ particles. These features were corresponding to the XRD results of MMIP we obtained previously (Fang et al. 2021). Such a surface characteristic was conducive to enhancing the 
photocatalytic degradation of the target at the interface. At the same time, numerous Bubble-like nanoholes can be observed on the surface, which may be formed by the imprinted cavity left by MMIP after removing the template molecules at high temperature. The porous structure of MMIP made it more specific and better to capture target pollutants. The chemical element composition of molecularly imprinted materials was analyzed by EDS, as shown in Fig. $1 \mathrm{~b}$, indicated the presence of $\mathrm{Co}, \mathrm{Fe}, \mathrm{Ti}, \mathrm{C}$ and $\mathrm{O}$ in MMIP, where the atomic ratios of $\mathrm{Ti} / \mathrm{O}$ and $\mathrm{Fe} / \mathrm{O}$ were $21.2 \%$ and $23.2 \%$, respectively. The sufficient $\mathrm{Ti}$ content provided a material basis for the photodegradation of norfloxacin.

\subsection{Photocatalytic degradation reaction kinetics}

The magnetic imprinted material had an anatase crystal structure after $\mathrm{CoFe}_{2} \mathrm{O}_{4}$ coated by the $\mathrm{TiO}_{2}$ layer and the surface modification of the molecular imprinting layer, which was conducive to photocatalysis of organic pollutants. Generally, the photocatalytic degradation reaction was a rate-limiting reaction that depended on the concentration of norfloxacin on the surface of the imprinted photocatalytic material and the concentration of hydroxyl radicals (Behnajady et al. 2007). It was assumed that the light intensity and the oxygen concentration in the solution remain unchanged during the process. Using the Langmuir model and considering the direct photodegradation of norfloxacin under ultraviolet light, the catalytic degradation rate equation of norfloxacin can be obtained as (Kumar and Porkodi 2008):

$r_{\mathrm{NOR}}=\frac{k_{\mathrm{c}} K_{\mathrm{NOR}}}{1+K_{\mathrm{NOR}} C_{\mathrm{NORO}}}+K^{\prime}$

Where $r_{\text {NOR }}$ was the comprehensive degradation rate of norfloxacin, $K_{\mathrm{NOR}}$ was the adsorption equilibrium constant of norfloxacin, $k_{\mathrm{c}}$ was the photocatalytic degradation rate constant of norfloxacin on material surface, $K^{\prime}$ was the direct photodegradation rate constant of norfloxacin under ultraviolet light and $C_{\mathrm{NORO}}$ was the initial concentration of norfloxacin.

Five different initial concentrations were selected to explore the catalytic degradation rate of the material. Figure 2a showed that the photocatalytic degradation rate of norfloxacin decreased by $77.3 \%$ when the initial concentration increased from $1 \mathrm{mg} \mathrm{L}^{-1}$ to $25 \mathrm{mg} \mathrm{L}^{-1}$. Figure $2 \mathrm{~b}$ displayed the fitting result of the photocatalytic degradation rate equation of norfloxacin. The main parameters are as follows: $k_{\mathrm{c}}=1.058$ $\mathrm{mg} \mathrm{L}^{-1} \mathrm{~min}^{-1}, K_{\mathrm{NOR}}=0.196 \mathrm{~L} \mathrm{~min}^{-1}$ and $K^{\prime}=0.008 \mathrm{~min}^{-1}$. So the final kinetic fitting equation for the photocatalytic degradation of norfloxacin by the imprinted photocatalytic material can be expressed as the following formula:

$r_{\mathrm{NOR}}=\frac{0.207}{1+0.196 C_{\mathrm{NORO}}}+0.008$

According to the fitting results, the rate constant of direct photodegradation of norfloxacin under ultraviolet light was relatively small. Most of norfloxacin molecules were adsorbed on the surface of MMIP, and could only degrade on its surface, so that the amount of norfloxacin available for photolysis in 
the solution was less. For the model fitting results without $K$ ', the $k_{\mathrm{c}}$ was $18.5 \%$ larger and the $K_{\mathrm{NOR}}$ was $14.3 \%$ smaller. Therefore, although the direct photodegradation rate constant of norfloxacin was small, this term in the equation cannot be ignored.

\subsection{Effect of environmental factors on photocatalytic degradation}

Similar to the adsorption performance, some environmental factors also affect the degradation behavior of norfloxacin by magnetic molecularly imprinting materials. We explored the effects of solution $\mathrm{pH}$, humic acid, common ions and water media on the photocatalytic degradation performance of MMIP.

\subsubsection{Solution $\mathrm{pH}$}

In the study of the adsorption performance of magnetic imprinting materials, it was found that $\mathrm{pH}$ had an evident impact on the adsorption and removal of norfloxacin (Fang et al. 2021). In this experiment, the pH of the solution was adjusted to 3-11 to further explore the effect of it on the photocatalytic degradation performance of MMIP. Due to the low discrimination of $\mathrm{pH}$ on the degradation process at a high dosage, the dosage was selected as $0.1 \mathrm{~g} \mathrm{~L}^{-1}$ to amplify the difference. The experimental results are shown in Fig. 3. When the $\mathrm{pH}$ was neutral, the photodegradation rate was the fastest, and the photocatalytic reaction rate constant was $0.075 \mathrm{~min}^{-1}$. Under acidic and alkaline conditions, especially at $\mathrm{pH}=11$, the photocatalytic degradation rate decreased significantly. This is mainly because the activity of the catalyst is closely related to the charged properties of its surface (Gumy et al. 2006). The electrostatic interaction of solvent molecules, target substances and hydroxyl radicals on the photocatalyst surface is greatly affected by $\mathrm{pH}$, which in turn affects the photocatalytic reaction rate. And low $\mathrm{pH}$ solution inhibited the hydrolysis of fluorine, while high $\mathrm{pH}$ solution enhanced the stability of piperazine rings in the structure (Paul et al. 2010). In addition, MMIP had the best adsorption effect on norfloxacin under neutral conditions, so more norfloxacin was adsorbed on the surface of the catalyst that also promoted the photocatalytic reaction process.

\subsubsection{Humic acid}

Humic acid is a common free radical trapping agent due to the presence of unsaturated functional groups, which reduces the efficiency of free radicals in the reaction system. In the degradation reaction of $\mathrm{TiO}_{2}$ as catalyst, humic acid served as a scavenger of hydroxyl radical, hindering the activity of $\mathrm{TiO}_{2}$ (Tang et al. 2018). Here, solutions with different humic acid concentrations were used as the reaction media, and their concentrations were characterized by TOC as TOC $1=0.154 \mathrm{mg} \mathrm{L}^{-1}, \mathrm{TOC}_{2}=1.823 \mathrm{mg} \mathrm{L}^{-}$ $1, \mathrm{TOC}_{3}=2.523 \mathrm{mg} \mathrm{L}^{-1}$, and $\mathrm{TOC}_{4}=4.427 \mathrm{mg} \mathrm{L}^{-1}$, respectively. The effect of humic acid on ultraviolet photocatalytic degradation of norfloxacin is shown in Fig. 4. Obviously, with the increase of humic acid concentration, the photocatalytic degradation rate decreased, and when the TOC concentration was 1.823 $\mathrm{mg} \mathrm{L}^{-1}$, the degradation rate decreased by $41.8 \%$, but the rate almost did not decrease in the low concentration of humic acid solution. Humic acid can occupy the specific adsorption site of imprinted material, thus reducing the adsorption and removal efficiency of norfloxacin. It should be noted the results of this experiment showed that the imprinted material still had a strong competitiveness in 
photocatalytic degradation of the target in the low concentration of humic acid environment, and norfloxacin could be completely degraded within $60 \mathrm{~min}$ in a highly concentrated humic acid solution. In the experiment of using $\mathrm{TiO}_{2}$ to degrade tetracycline under UVA-LED light, the photocatalytic degradation efficiency was reduced by $75.5 \%$ in the presence of $1 \mathrm{mg} \mathrm{L}^{-1}$ humic acid, but the efficiency was almost unchanged with the increase of humic acid concentration (Li and Hu 2016).

\subsubsection{Common ions}

The actual water body composition is more complex and contains a lot of ions. In order to explore the influence of different ions on the photocatalytic degradation of norfloxacin by MMIP, $\mathrm{Na}^{+}, \mathrm{Fe}^{3+}, \mathrm{SO}, \mathrm{NO}$

with a concentration of $0.1 \mathrm{mM}$ were selected as experimental ions. As shown in Fig. $5, \mathrm{Fe}^{3+}$ and NO had conspicuous impact on degradation rate, and the other two ions had no obvious influence. Various ions had different effects on the adsorption of norfloxacin by MMIP in the initial adsorption process, and the photocatalytic performance of the material was the best when the $\mathrm{pH}$ was neutral. However, the cations and anions would affect the $\mathrm{pH}$ value of the solution, thereby changing the charging properties of reducing substances and photocatalytic materials. In addition, the ions could react with the surface adsorption sites of the photocatalytic material to affect the photocatalytic reaction (Gumy et al. 2006). $\mathrm{Take}^{3+}$ for example, the presence of $\mathrm{Fe}^{3+}$ will significantly reduce the photochemical reaction rate, mainly due to the negative effect of $\mathrm{Fe}^{3+}$ on the adsorption stage (Fang et al. 2021). Secondly, the hydrolysis of $\mathrm{Fe}^{3+}$ will reduce the $\mathrm{pH}$ value of the solution, altering the electrostatic interaction between the photocatalyst surface and solvent molecules, target substances and hydroxyl radicals, respectively. Chen et al. (2017) found that $\mathrm{Fe}^{3+}$ could reduce the number of oxygen-containing free radicals in the photocatalytic chain reaction by trapping photoelectrons. In addition, the presence of NO in a photocatalytic system will affect the binding of the target substance to hydroxyl radicals (Tang et al. 2016).

\subsubsection{Water media}

The practical application of the material was tested and ultrapure water, tap water and surface water samples were selected as the reaction media. The common water quality indexes of each water body sample are shown in Table 1. Figure 6 revealed that surface water had the greatest weakening effect on the photocatalytic degradation of norfloxacin, and the degradation rate constant was reduced to 0.050 $\min ^{-1}$. The main reasons that weaken the degradation rate may come down to three aspects. The first is the influence of water turbidity. For surface water, because of its high turbidity and poor transmission of ultraviolet light, the intensity of illumination would decrease when it reached the surface of MMIP. Colloid particles and suspended solids in the water can absorb and scatter some of the light so that the production efficiency of hydroxyl radical would be reduced accordingly. The effect of dissolved compounds on the degradation of norfloxacin by MMIP was also obvious. Especially, the presence of anions and cations such as $\mathrm{Fe}^{3+}$ and $\mathrm{NO}$ in natural waters will reduce the generation rate of hydroxyl radicals. Humic acid and other substances could compete with the target substances for hydroxyl radicals and photons, resulting in the decrease of the photocatalytic degradation rate of the target substances. The third aspect is that the selective adsorption ability of imprinted materials to norfloxacin 
is different in water media. In surface water, the adsorption removal efficiency of norfloxacin was relatively low, reducing the possibility of hydroxyl radical colliding with norfloxacin. Nevertheless, the photocatalytic degradation process could still be degraded in a short time, implying the photocatalytic degradation performance of magnetic imprinted materials has satisfied adaptability in different water media.

Table 1

Conventional water quality indexes for surface water and tap water samples

\begin{tabular}{|lll|}
\hline Water quality indexes & Surface water & Tap water \\
\hline $\mathrm{pH}$ & 7.94 & 6.78 \\
\hline $\mathrm{UV}_{254}$ & 0.033 & 0.010 \\
\hline $\mathrm{TOC}\left(\mathrm{mg} \mathrm{L}^{-1}\right)$ & 13.590 & 3.242 \\
\hline $\mathrm{Na}^{+}\left(\mathrm{mg} \mathrm{L}^{-1}\right)$ & 14.690 & 12.840 \\
\hline $\mathrm{K}^{+}\left(\mathrm{mg} \mathrm{L}^{-1}\right)$ & 3.623 & 2.577 \\
\hline $\mathrm{Fe}^{3+}\left(\mathrm{mg} \mathrm{L}^{-1}\right)$ & 0.383 & 0.271 \\
\hline $\mathrm{SO}\left(\mathrm{mg} \mathrm{L}^{-1}\right)$ & 98.400 & 41.700 \\
\hline $\mathrm{NO}\left(\mathrm{mg} \mathrm{L}^{-1}\right)$ & 15.610 & 9.870 \\
\hline
\end{tabular}

\subsection{Photocatalytic degradation reaction mechanism}

\subsubsection{Identification of photocatalytic degradation products}

In order to in-depth research the process and mechanism of photocatalytic degradation of norfloxacin by MMIP, the degradation products of norfloxacin were qualitatively analyzed by liquid chromatographymass spectrometry. As the illumination time increases, the number of peaks in the mass spectrum continues to increase, which means that new substances are constantly being produced. Figure 7 lists the mass spectrogram corresponding to some chromatographic peaks.

The modification of molecularly imprinted layer on the surface of $\mathrm{TiO}_{2}$ can improve the adsorption performance of the material, thereby increasing the degradation efficiency of target pollutants (de Escobar et al. 2018). However, the photocatalytic mechanism still belongs to advanced oxidation reaction. According to the analysis of the molecular weight of the product, a total of nine intermediates were detected and the possible molecular structures were proposed. Products 1 to 4 indicated the gradual degradation process of piperazine ring on the benzene ring. The hydrogen on the methyl was replaced by hydroxyl, which was then oxidized to ketone, and the ring was further disconnected until only an amino group was left in the original position of piperazine ring. Product 5 with a protonated form of $\mathrm{m} / \mathrm{z} 276$ was in all probability formed due to the removal of the carboxyl. The formation of product 6 might be 
derived from two degradation pathways. It is the basic molecular structure of fluoroquinolone antibiotics and lacks the piperazine ring and carboxyl group compared with norfloxacin. In a complex system of photocatalysis, the sequence in which the piperazine ring and carboxyl groups were degraded and removed was not clear, but the resulting product may have the same structure. The other two products 7 and 8 with the $\mathrm{m} / \mathrm{z}$ of 318 and 249 respectively, reflecting that fluorine on the benzene ring was likely to be replaced by hydroxyl in the degradation process. Another product 9 also demonstrated the likelihood of direct removal of fluorine by photocatalytic degradation. The possible reaction pathway is deduced and summarized as shown in Fig. 8. On the whole, the photocatalytic degradation rate of norfloxacin by ultraviolet is fast, and the formative specific adsorption sites might re-adsorb the target, realizing the completely removal of pollutants.

\subsubsection{Mineralization ratio}

The mineralization ratio in the photocatalytic system is represented by the removal efficiency of TOC. The trend of the mineralization ratio during the photocatalytic degradation of norfloxacin by MMIP material is shown in Fig. 9. After 150 min of irradiation under ultraviolet light, the mineralization of norfloxacin was basically stable, reaching a maximum of $84.2 \%$. Compared with other methods, the mineralization ratio of ultraviolet photocatalytic degradation is higher (Estrada-Flórez et al. 2020), and some comparison results are displayed in Table 2. The degree of mineralization of organic pollutants was relatively high in the reaction process, which indicated norfloxacin was finally degraded into inorganic small molecules after photocatalytic degradation, showing a well ecological friendliness and application value.

Table 2

Comparison of mineralization ratios of norfloxacin photocatalytic degradation by different materials

\begin{tabular}{|c|c|c|c|c|c|}
\hline Photocatalyst & Reaction conditions & $\begin{array}{l}\text { Light } \\
\text { source }\end{array}$ & $\begin{array}{l}\text { Time } \\
(\min )\end{array}$ & $\begin{array}{l}\text { Mineralization } \\
\text { ratio }\end{array}$ & Reference \\
\hline $\begin{array}{l}\mathrm{BiOBr} / \mathrm{UiO}-66- \\
\mathrm{NH}_{2}\end{array}$ & $\begin{array}{l}\mathrm{NOR}=10.0 \mathrm{mg} \mathrm{L}^{-1} \\
\text { dosage }=0.3 \mathrm{~g} \mathrm{~L}^{-1}\end{array}$ & $\begin{array}{l}\text { Simulated } \\
\text { solar light }\end{array}$ & 270 & $60.58 \%$ & $\begin{array}{l}\text { (Yang et } \\
\text { al. 2019) }\end{array}$ \\
\hline $\mathrm{Bi} / \mathrm{Fe}-\mathrm{ZnO}$ & $\begin{array}{l}\mathrm{NOR}=20.0 \mathrm{mg} \mathrm{L}^{-1}, \mathrm{HSO}= \\
0.6 \mathrm{mM} \text { dosage }=2.0 \mathrm{~g} \mathrm{~L}^{-1}\end{array}$ & $\begin{array}{l}\text { Simulated } \\
\text { solar light }\end{array}$ & 400 & $65.0 \%$ & $\begin{array}{l}\text { (Shah et } \\
\text { al. 2018) }\end{array}$ \\
\hline $\mathrm{Ag} / \mathrm{AgCl}-\mathrm{CeO}_{2}$ & $\begin{array}{l}\text { NOR }=10.0 \mathrm{mg} \mathrm{L}^{-1} \text {, dosage } \\
=0.6 \mathrm{~g} \mathrm{~L}^{-1}\end{array}$ & $\begin{array}{l}\text { Visible } \\
\text { light }\end{array}$ & 150 & $59.61 \%$ & $\begin{array}{l}\text { (Wen et } \\
\text { al. 2017) }\end{array}$ \\
\hline Graphene/ $\mathrm{TiO}_{2}$ & $\begin{array}{l}\text { NOR }=20.0 \mathrm{mg} \mathrm{L}^{-1} \text {, dosage } \\
=1.0 \mathrm{~g} \mathrm{~L}^{-1}\end{array}$ & $\begin{array}{l}\text { Simulated } \\
\text { solar light }\end{array}$ & 600 & $86.2 \%$ & $\begin{array}{l}\text { (Li et al. } \\
\text { 2013) }\end{array}$ \\
\hline MMIP & $\begin{array}{l}\mathrm{NOR}=2.0 \mathrm{mg} \mathrm{L}^{-1} \\
\text { dosage }=0.4 \mathrm{~g} \mathrm{~L}^{-1}\end{array}$ & $\begin{array}{l}\text { Ultraviolet } \\
\text { light }\end{array}$ & 150 & $84.2 \%$ & This work \\
\hline
\end{tabular}

3.5 Material stability and safety 


\subsubsection{Assessment of regeneration capacity}

The performance of photocatalytic regeneration and recycling of magnetic imprinted materials was also studied. Adsorption was performed for two hours to reach saturation, and then photocatalytic in-situ regeneration was performed for two hours. After that, the concentration of norfloxacin in the solution was reset to the initial concentration, and the next round of adsorption experiment was replicated. The recycling performance of the magnetic imprinted material is shown in Fig. 10. After seven cycles, the total removal efficiency of norfloxacin could still reach $99.0 \%$, and the adsorption performance did not decrease significantly, indicating the excellent recycling ability of MMIP. Norfloxacin can be desorbed automatically and release the active sites after degrading into small molecule structure, so as to achieve in-situ regeneration. Compared with other regeneration methods, such as acid-base elution, organic solvent elution and calcination, using advanced oxidation technology is more effective, and ultraviolet photocatalytic regeneration method has the advantages of convenience and environmental protection.

\subsubsection{Cobalt release}

A release experiment of cobalt from the material was conducted as a safety evaluation. Excessive discharge of cobalt-containing wastewater has an impact on the environment, and its toxicity to aquatic animals and crops is greater (Chen et al. 2020). The amount of cobalt in environmental waters is stipulated not to exceed $0.05 \mathrm{mg} \mathrm{L}^{-1}$ (Saad et al. 2020). Take the basic carrier as a comparison, $\mathrm{CoFe}_{2} \mathrm{O}_{4}$ and MMIP materials of $0.4 \mathrm{~g} \mathrm{~L}^{-1}$ were added to the deionized water, respectively. The solutions were kept stirring, and samples were taken every day to determine the concentration of cobalt released. The results are shown in Fig. 11. During the testing period of 10 days, the cobalt release concentration of $\mathrm{CoFe}_{2} \mathrm{O}_{4}$ increased gradually and reached $124.30 \mathrm{~g} \mathrm{~L}^{-1}$ on the 10 th day. Correspondingly, the release concentration of cobalt in MMIP material was significantly lower than that of $\mathrm{CoFe}_{2} \mathrm{O}_{4}$, and the cobalt concentration in the solution was relatively stable, which the average cobalt concentration measured in 10 days was $4.22 \mathrm{\mu g} \mathrm{L}^{-1}$. It can be seen that after the modification of molecularly imprinted layer, the metal precipitation behavior of the material is controlled, and the enhancement of safety performance improves the application potential of the material.

\section{Conclusion}

In summary, the novel magnetic molecularly imprinted polymers can effectively degrade norfloxacin under ultraviolet light and has the ability of in-site regeneration and sustainable utilization. The successful synthesis of the imprinted titanium layer and the porous surface enhance the photocatalytic degradation of the target template molecules at the interface. The fitting kinetic equation showed that the degradation rate of norfloxacin with low concentration was higher by imprinted photocatalyst. Humic acid and common ions can influence the degradation rate of norfloxacin, among which $\mathrm{Fe}^{3+}$ had the most significant effect. The main pathways of the photocatalytic degradation of norfloxacin were proposed, including transformation and removal of piperazine rings, decarboxylation and replacement or direct removal of fluorine. After 150 min of ultraviolet light irradiation, norfloxacin was eventually 
degraded with a high mineralization ratio of $84.2 \%$, accompanied by the release of specific adsorption sites, thus achieving in-situ regeneration of the material. The content of cobalt released by MMIP was far below than that of cobalt ferrite nanoparticles, indicating that molecular imprinting technology was conducive to reduce the release of cobalt. This study showed that MMIP was an attractive and potential material to treat trace amounts of antibiotics in water.

\section{Declarations}

Ethics approval Not applicable

Consent to participate Not applicable

Consent for publication Not applicable

\section{Availability of data and materials}

All data generated or analyzed during this study are included in this published article [and its supplementary information files].

\section{Competing interests}

The authors declare that they have no competing interests.

\section{Funding}

This research was financially supported by the National Natural Science Foundation of China (No. 51808489), the Fundamental Research Funds for the Central Universities of China (No. 2020QNA4030) and the National Science and Technology Major Project for Water Pollution Control and Treatment of China (No. 2017ZX07201003).

\section{Authors' contributions}

LF: Supervision, methodology, interpretation of data, writing-review and editing. KT and DW: Experimental operation, formal analysis, writing-original draft preparation. $\mathrm{YZ}$ and $\mathrm{YZ}$ : Interpretation of data, writing-review and editing. All authors read and approved the final manuscript.

\section{Acknowledgements}

The authors are thankful to the laboratory management teacher Sijia Chen for her assistance and guidance in the use of the instruments.

\section{References}


1. Barahona F, Albero B, Tadeo JL, Martin-Esteban A (2019) Molecularly imprinted polymer-hollow fiber microextraction of hydrophilic fluoroquinolone antibiotics in environmental waters and urine samples. J Chromatogr A 1587:42-49. https://doi.org/10.1016/j.chroma.2018.12.015

2. Behnajady MA, Modirshahla N, Daneshvar N, Rabbani M (2007) Photocatalytic degradation of an azo dye in a tubular continuous-flow photoreactor with immobilized $\mathrm{TiO}_{2}$ on glass plates. Chem Eng J 127:167-176. https://doi.org/10.1016/j.cej.2006.09.013

3. BelBruno JJ (2019) Molecularly Imprinted Polymers. Chem Rev 119:94-119. https://doi.org/10.1021/acs.chemrev.8b00171

4. Carvalho IT, Santos $L$ (2016) Antibiotics in the aquatic environments: A review of the European scenario. Environ Int 94:736-757. https://doi.org/10.1016/j.envint.2016.06.025

5. Chen C, Xu C, Qian D, Yu Q, Huang M, Zhou L, Qin J, Chen L, Li E (2020) Growth and health status of Pacific white shrimp, Litopenaeus vannamei, exposed to chronic water born cobalt. Fish Shellfish Immunol 100:137-145. https://doi.org/10.1016/j.fsi.2020.03.011

6. Chen Y, Wang A, Zhang Y, Bao R, Tian X, Li J (2017) Electro-Fenton degradation of antibiotic ciprofloxacin (CIP): Formation of $\mathrm{Fe}^{3+}-\mathrm{CIP}$ chelate and its effect on catalytic behavior of $\mathrm{Fe}^{2+} / \mathrm{Fe}^{3+}$ and CIP mineralization. Electrochim Acta 256:185-195. https://doi.org/10.1016/j.electacta.2017.09.173

7. de Escobar CC, Moreno Ruiz YP, dos Santos JHZ, Ye L (2018) Molecularly imprinted $\mathrm{TiO}_{2}$ photocatalysts for degradation of diclofenac in water. Colloids Surf A-Physicochem Eng Asp 538:729-738. https://doi.org/10.1016/j.colsurfa.2017.11.044

8. de Souza Santos LV, Teixeira DC, Jacob RS, Amaral MC, Lange LC (2014) Evaluation of the aerobic and anaerobic biodegradability of the antibiotic norfloxacin .Water Sci Technol 70:265-271. https://doi.org/10.2166/wst.2014.214

9. Dong H, Zeng G, Tang L, Fan C, Zhang C, He X, He Y (2015) An overview on limitations of $\mathrm{TiO}_{2}$-based particles for photocatalytic degradation of organic pollutants and the corresponding countermeasures. Water Res 79:128-146. https://doi.org/10.1016/j.watres.2015.04.038

10. Du Q, Wu P, Sun Y, Zhang J, He H (2020) Selective photodegradation of tetracycline by molecularly imprinted ZnO@NH 2 -UiO-66 composites. Chem Eng J 390:124614. https://doi.org/10.1016/j.cej.2020.124614

11. Estrada-Flórez SE, Serna-Galvis EA, Torres-Palma RA (2020) Photocatalytic vs. sonochemical removal of antibiotics in water: Structure-degradability relationship, mineralization, antimicrobial activity, and matrix effects. J Environ Chem Eng 8:104359.

https://doi.org/0.1016/j.jece.2020.104359

12. Fang L, Miao Y, Wei D, Zhang Y, Zhou Y (2021) Efficient removal of norfloxacin in water using magnetic molecularly imprinted polymer. Chemosphere 262:128032.

https://doi.org/10.1016/j.chemosphere.2020.128032 
13. Gumy D, Morais C, Bowen P, Pulgarin C, Giraldo S, Hajdu R, Kiwi J (2006) Catalytic activity of commercial of $\mathrm{TiO}_{2}$ powders for the abatement of the bacteria (E. coli) under solar simulated light: Influence of the isoelectric point. Appl Catal B-Environ 63:76-84. https://doi.org/10.1016/j.apcatb.2005.09.013

14. Huang F, An Z, Moran MJ, Liu F (2020) Recognition of typical antibiotic residues in environmental media related to groundwater in China (2009-2019). J Hazard Mater 399:122813. https://doi.org/10.1016/j.jhazmat.2020.122813

15. Jiang Y, Shi K, Tang H, Wang Y (2019) Enhanced wettability and wear resistance on $\mathrm{TiO}_{2} / \mathrm{PDA}$ thin films prepared by sol-gel dip coating. Surf Coat Technol 375:334-340. https://doi.org/10.1016/j.surfcoat.2019.07.051

16. Kumar A, Khan M, Fang L, Lo IMC (2019) Visible-light-driven $\mathrm{N}-\mathrm{TiO}_{2} @ \mathrm{SiO}_{2} @ \mathrm{Fe}_{3} \mathrm{O}_{4}$ magnetic nanophotocatalysts: Synthesis, characterization, and photocatalytic degradation of PPCPs. J Hazard Mater 370:108-116. https://doi.org/10.1016/j.jhazmat.2017.07.048

17. Kumar KV, Porkodi K (2008) Comments on "Photocatalytic properties of $\mathrm{TiO}_{2}$ modified with platinum and silver nanoparticles in the degradation of oxalic acid in aqueous solution": Langmuir Hinshelwood kinetics-A theoretical study. Appl Catal B-Environ 79:108-109. https://doi.org/10.1016/j.apcatb.2007.09.041

18. Li K, Xiong J, Chen T, Yan L, Dai Y, Song D, Lv Y, Zeng Z (2013) Preparation of graphene/ $/ \mathrm{TiO}_{2}$ composites by nonionic surfactant strategy and their simulated sunlight and visible light photocatalytic activity towards representative aqueous POPs degradation. J Hazard Mater 250251:19-28. https://doi.org/10.1016/j.jhazmat.2013.01.069

19. Li S, Hu J (2016) Photolytic and photocatalytic degradation of tetracycline: Effect of humic acid on degradation kinetics and mechanisms. J Hazard Mater 318:134-144. https://doi.org/10.1016/j.jhazmat.2016.05.100

20. Paul T, Dodd MC, Strathmann TJ (2010) Photolytic and photocatalytic decomposition of aqueous ciprofloxacin: Transformation products and residual antibacterial activity. Water Res 44:3121-3132. https://doi.org/10.1016/j.watres.2010.03.002

21. Pestana CJ, Edwards C, Prabhu R, Robertson PKJ, Lawton LA (2015) Photocatalytic degradation of eleven microcystin variants and nodularin by $\mathrm{TiO}_{2}$ coated glass microspheres. J Hazard Mater 300:347-353. https://doi.org/10.1016/j.jhazmat.2015.07.016

22. Saad DR, Alismaeel ZT, Abbar AH (2020) Cobalt removal from simulated wastewaters using a novel flow-by fixed bed bio-electrochemical reactor. Chem Eng Process 156:108097. https://doi.org/10.1016/j.cep.2020.108097

23. Sajini T, Gigimol MG, Mathew B (2019) A brief overview of molecularly imprinted polymers supported on titanium dioxide matrices. Mater Today Chem 11:283-295. https://doi.org/10.1016/j.mtchem.2018.11.010 
24. Shah NS et al (2018) Solar light driven degradation of norfloxacin using as-synthesized $\mathrm{Bi}^{3+}$ and $\mathrm{Fe}^{2+}$ co-doped $\mathrm{ZnO}$ with the addition of $\mathrm{HSO}-5$ : Toxicities and degradation pathways investigation. Chem Eng J 351:841-855. https://doi.org/10.1016/j.cej.2018.06.111

25. Shan AY, Ghazi TIM, Rashid SA (2010) Immobilisation of titanium dioxide onto supporting materials in heterogeneous photocatalysis: A review. Appl Catal A-Gen 389:1-8. https://doi.org/10.1016/j.apcata.2010.08.053

26. Shen X, Zhu L, Wang N, Ye L, Tang H (2012) Molecular imprinting for removing highly toxic organic pollutants. Chem Commun 48:788-798. https://doi.org/10.1039/c2cc14654a

27. Tan F, Sun D, Gao J, Zhao Q, Wang X, Teng F, Quan X, Chen J (2013) Preparation of molecularly imprinted polymer nanoparticles for selective removal of fluoroquinolone antibiotics in aqueous solution. J Hazard Mater 244-245:750-757. https://doi.org/10.1016/j.jhazmat.2012.11.003

28. Tang T, Lu G, Wang W, Wang R, Huang K, Qiu Z, Tao X, Dang Z (2018) Photocatalytic removal of organic phosphate esters by $\mathrm{TiO}_{2}$ : Effect of inorganic ions and humic acid. Chemosphere 206:26-32. https://doi.org/10.1016/j.chemosphere.2018.04.161

29. Wang T, Zhang L, Li C, Yang W, Song T, Tang C, Meng Y, Dai S, Wang H, Chai L, Luo J (2015) Synthesis of core-shell magnetic $\mathrm{Fe}_{3} \mathrm{O}_{4} @$ poly (m-phenylenediamine) particles for chromium reduction and adsorption. Environ Sci Technol 49:5654-5662. https://doi.org/10.1021/es5061275

30. Wei D, Li S, Fang L, Zhang Y (2018) Effect of environmental factors on enhanced adsorption and photocatalytic regeneration of molecular imprinted $\mathrm{TiO}_{2}$ polymers for fluoroquinolones. Environ Sci Pollut Res 25:6729-6738. https://doi.org/10.1007/s11356-017-0949-3

31. Wen X, Niu C, Huang D, Zhang L, Liang C, Zeng G (2017) Study of the photocatalytic degradation pathway of norfloxacin and mineralization activity using a novel ternary $\mathrm{Ag} / \mathrm{AgCl}-\mathrm{CeO}_{2}$ photocatalyst. J Catal 355:73-86. https://doi.org/10.1016/j.jcat.2017.08.028

32. Wu X, Huang M, Zhou T, Mao J (2016) Recognizing removal of norfloxacin by novel magnetic molecular imprinted chitosan $/ \mathrm{Y}-\mathrm{Fe}_{2} \mathrm{O}_{3}$ composites: Selective adsorption mechanisms, practical application and regeneration. Sep Purif Technol 165:92-100. https://doi.org/10.1016/j.seppur.2016.03.041

33. Xi J, Liu J, He S, Shen W, Wei C, Li K, Zhang Y, Yue J, Yang Z (2019) Effects of norfloxacin exposure on neurodevelopment of zebrafish (Danio rerio) embryos. Neurotoxicology 72:85-94. https://doi.org/10.1016/ j.neuro.2019.02.007

34. Yang Z, Tong X, Feng J, He S, Fu M, Niu X, Zhang T, Liang H, Ding A, Feng X (2019) Flower-like $\mathrm{BiOBr} / \mathrm{UiO}-66-\mathrm{NH}_{2}$ nanosphere with improved photocatalytic property for norfloxacin removal. Chemosphere 220:98-106. https://doi.org/10.1016/j.chemosphere.2018.12.086

35. Yao Y, Lu F, Zhu Y, Wei F, Liu X, Lian C, Wang S (2015) Magnetic core-shell CuFe $\mathrm{O}_{4} @ \mathrm{C}_{3} \mathrm{~N}_{4}$ hybrids for visible light photocatalysis of Orange II. J Hazard Mater 297:224-233. https://doi.org/10.1016/j.jhazmat.2015.04.046 
36. Ye J, Li X, Li Q, Qiu T, Guo L, He L, Li X (2019) The building of molecular imprinted sites on the Stöber spheres of resorcinol-formaldehyde resin: In situ organic vs. inorganic imprinting method. Mater Chem Phys 230:239-248. https://doi.org/10.1016/j.matchemphys.2019.03.057

37. Zhang W, Li Y, Wang Q, Wang C, Wang P, Mao K (2013) Performance evaluation and application of surface-molecular-imprinted polymer-modified $\mathrm{TiO}_{2}$ nanotubes for the removal of estrogenic chemicals from secondary effluents. Environ Sci Pollut Res 20:1431-1440. https://doi.org/10.1007/s11356-012-0983-0

\section{Figures}



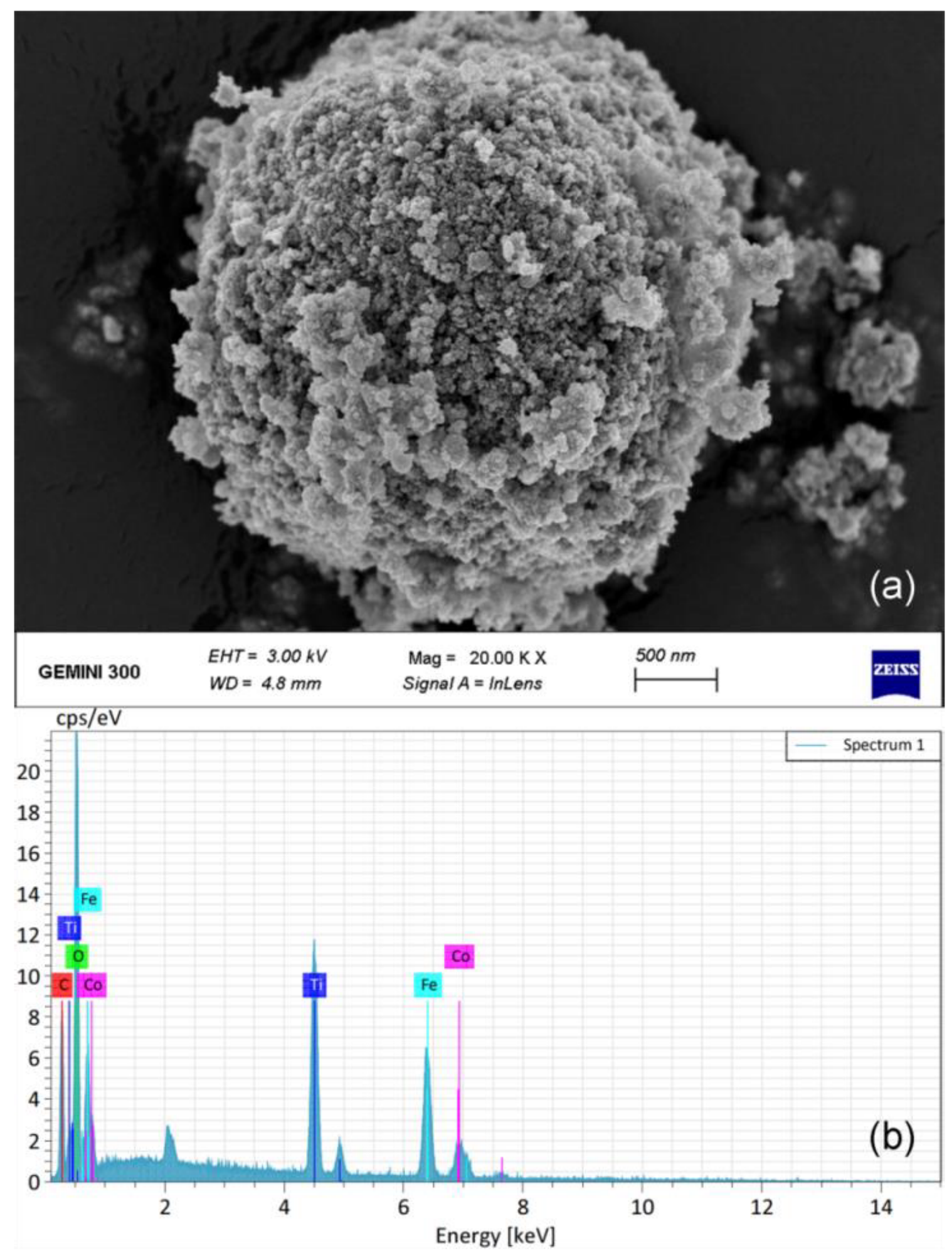

Figure 1

SEM image (a) and EDS (b) of the synthesized MMIP 

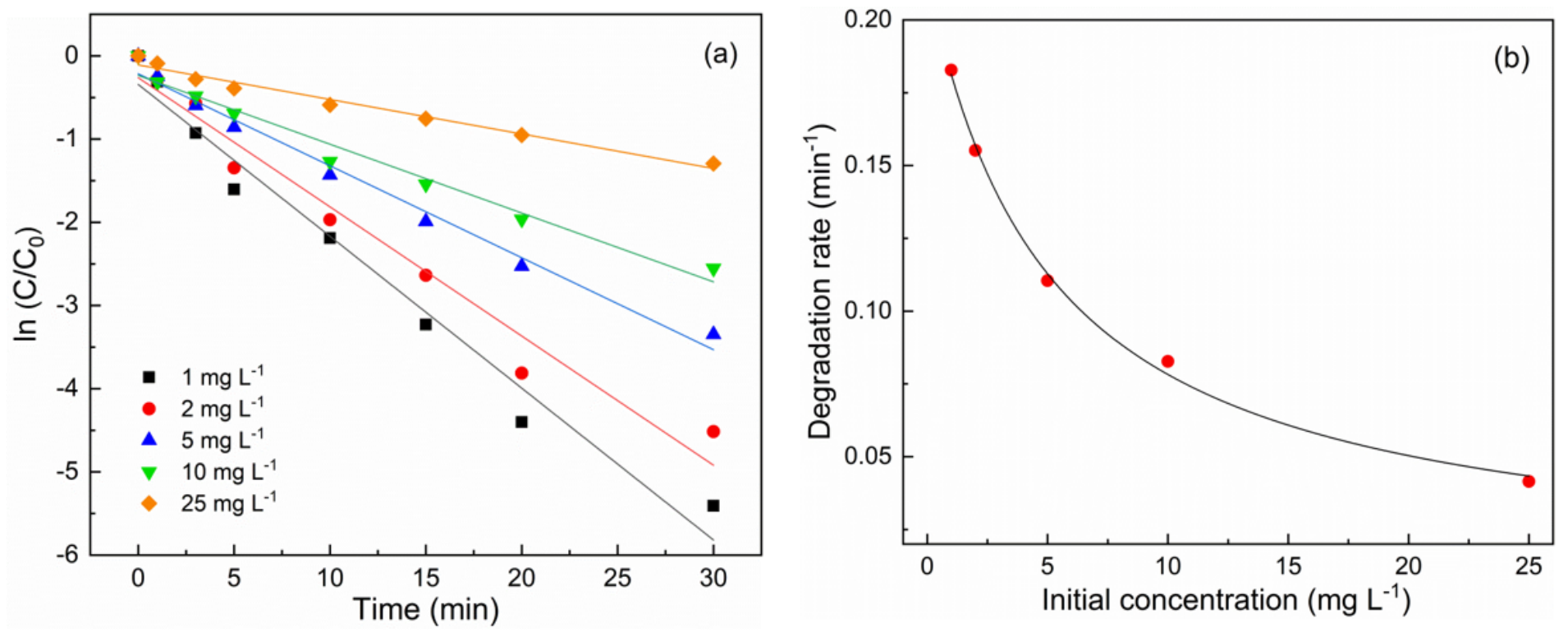

Figure 2

Kinetics (a) and fitting (b) of photocatalytic degradation of norfloxacin by MMIP

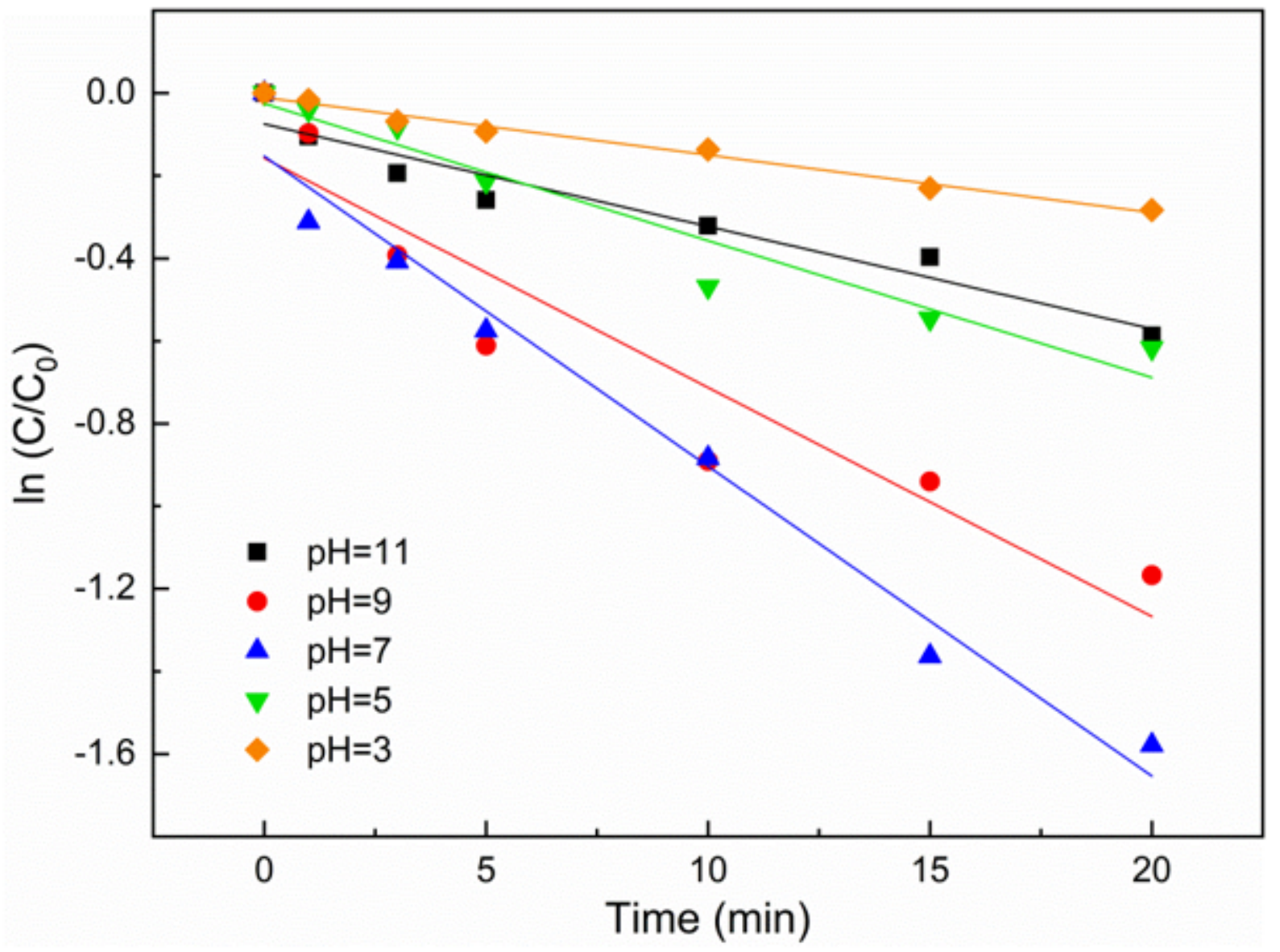

Figure 3

Influence of solution $\mathrm{pH}$ on photocatalytic degradation of norfloxacin by MMIP 


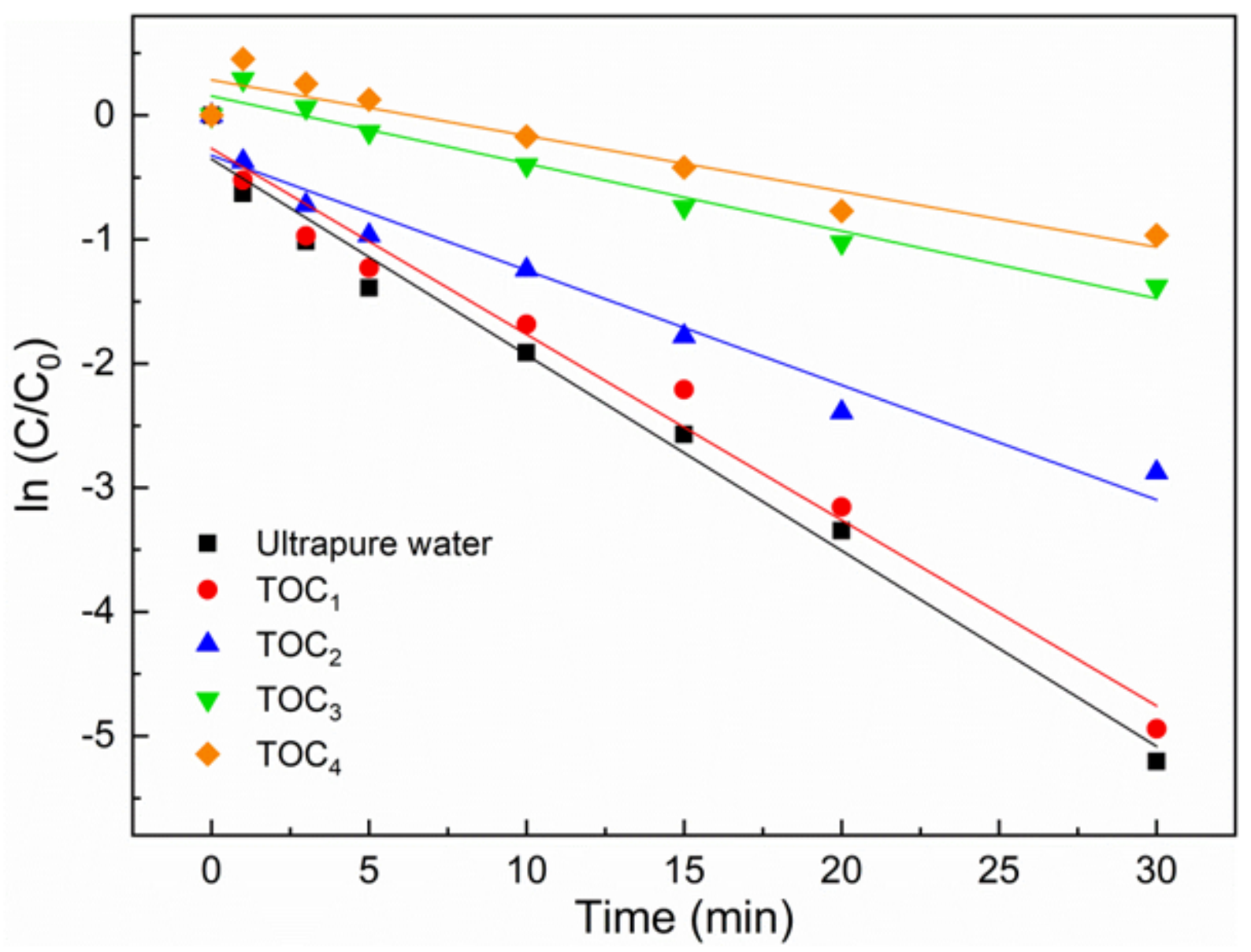

Figure 4

Influence of humic acid on photocatalytic degradation of norfloxacin by MMIP 


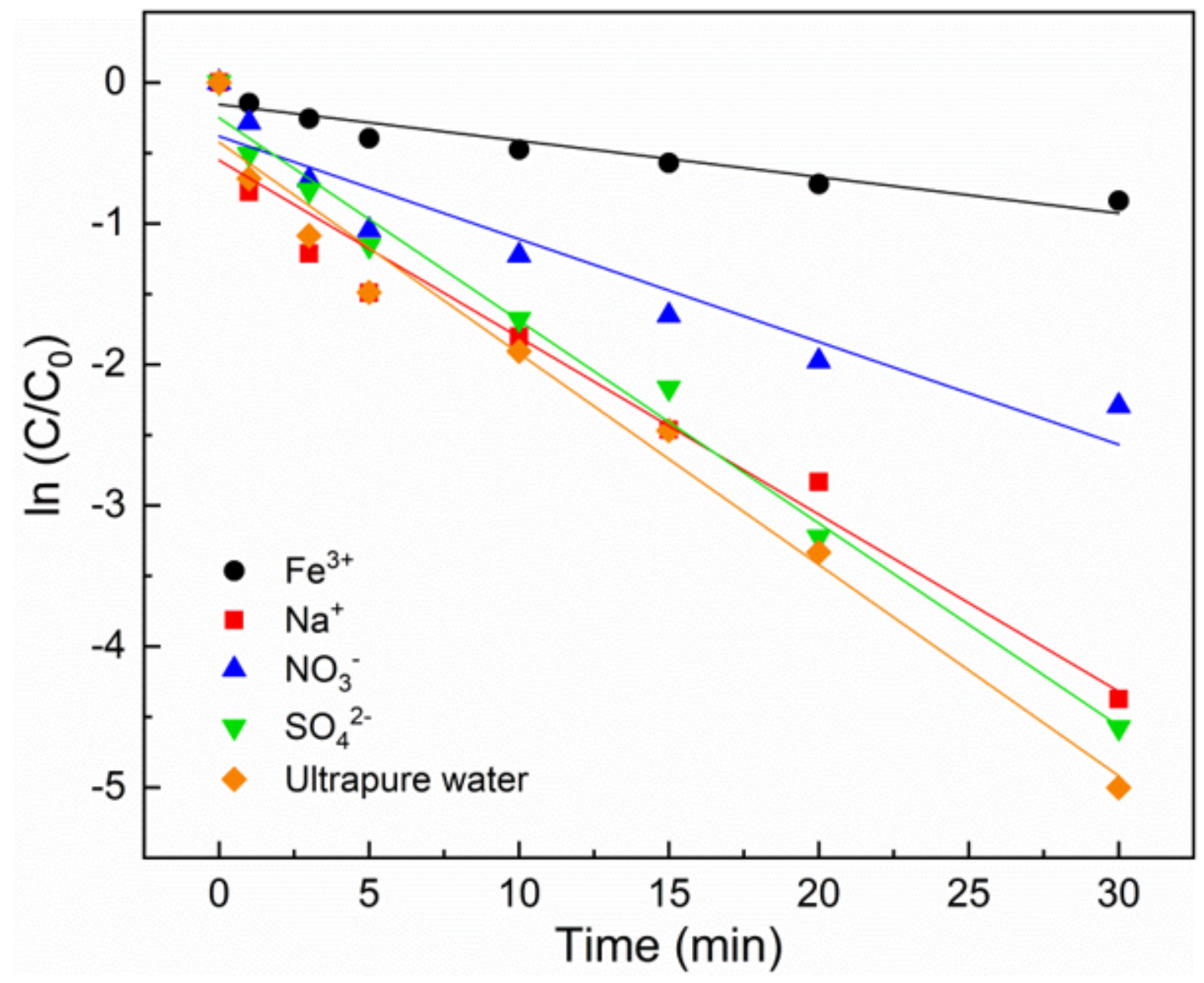

Figure 5

Influence of common ions on photocatalytic degradation of norfloxacin by MMIP 


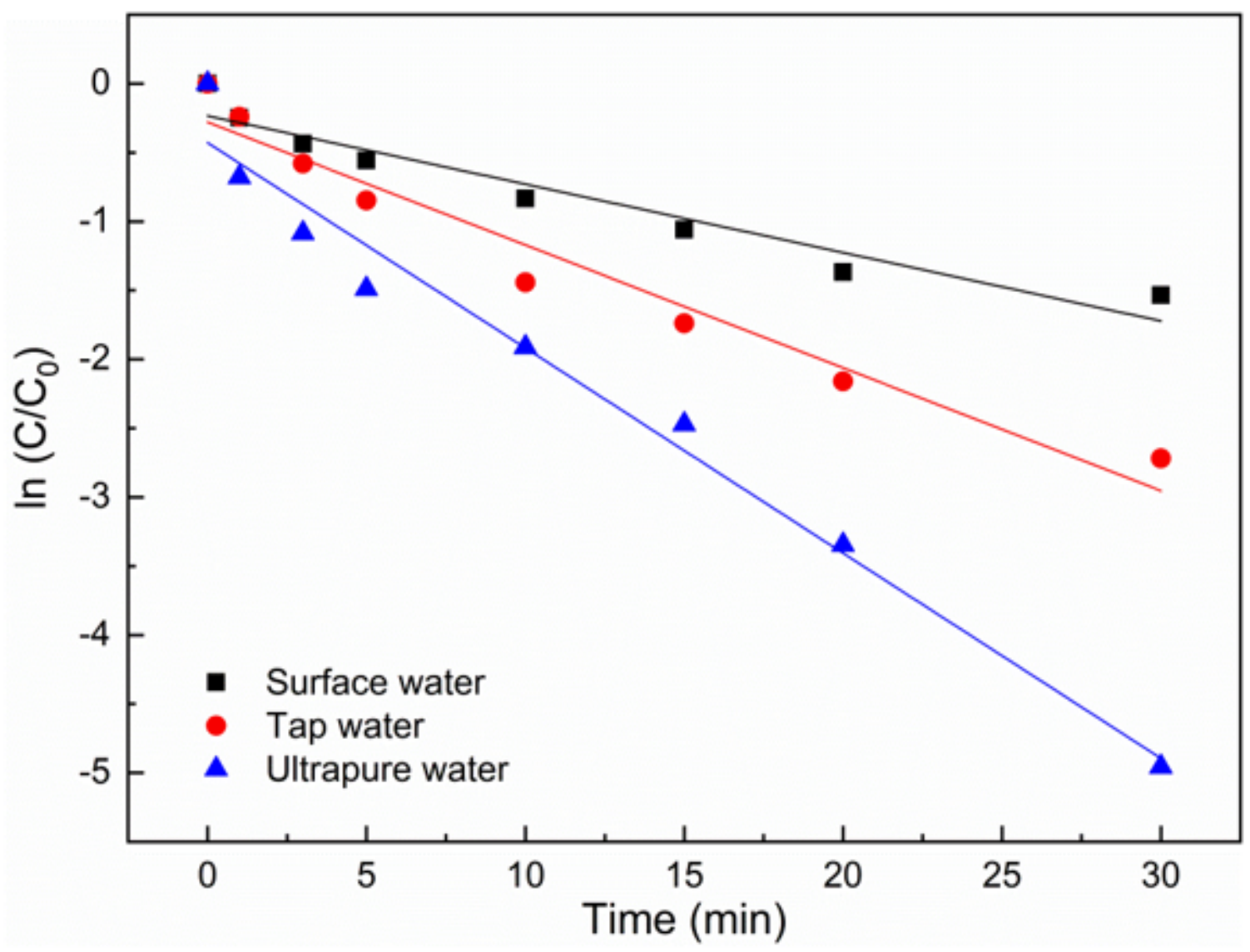

Figure 6

Influence of water mediums on photocatalytic degradation of norfloxacin by MMIP 

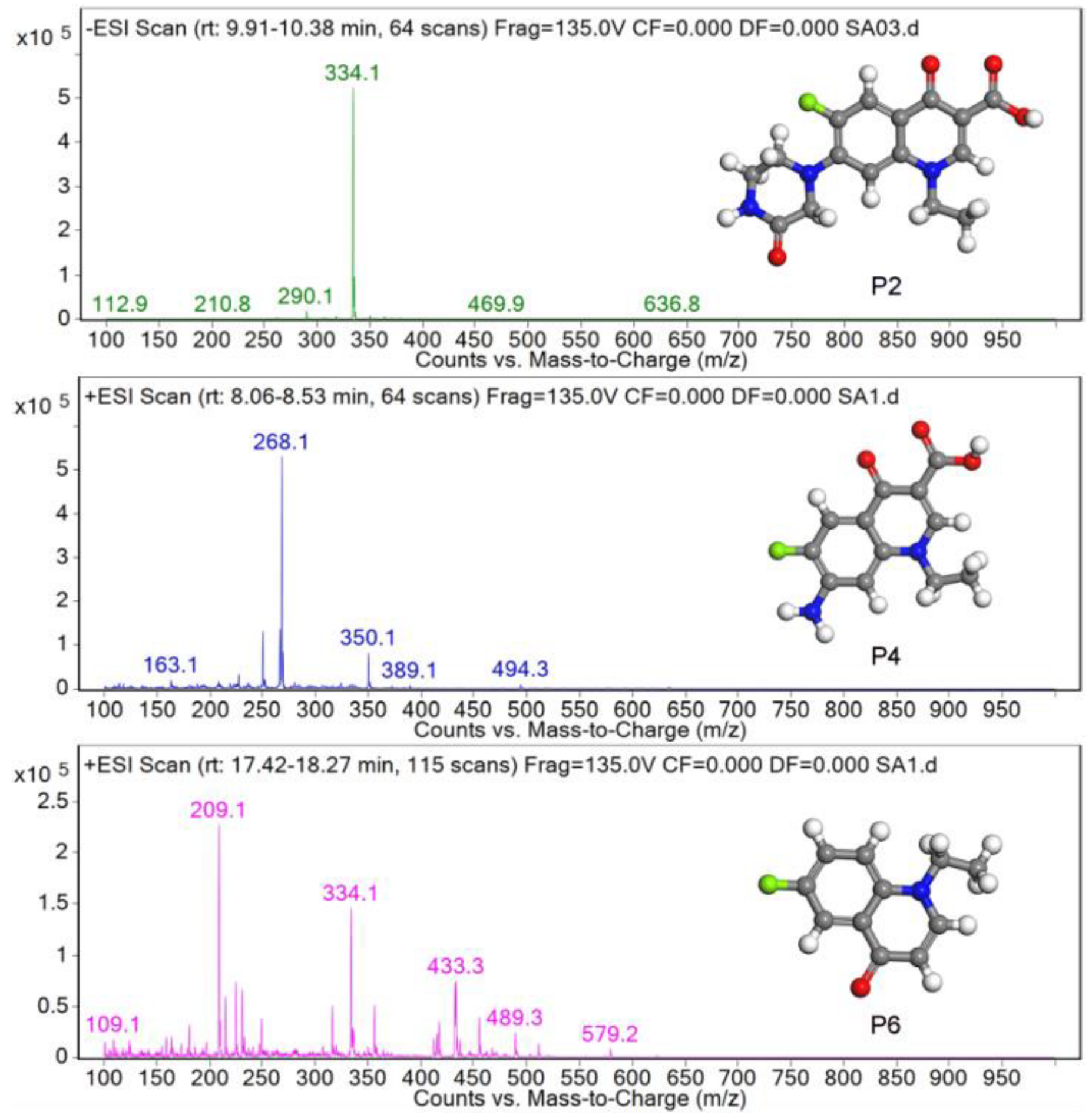

Figure 7

Part of the mass spectrogram corresponding to the chromatographic peaks 


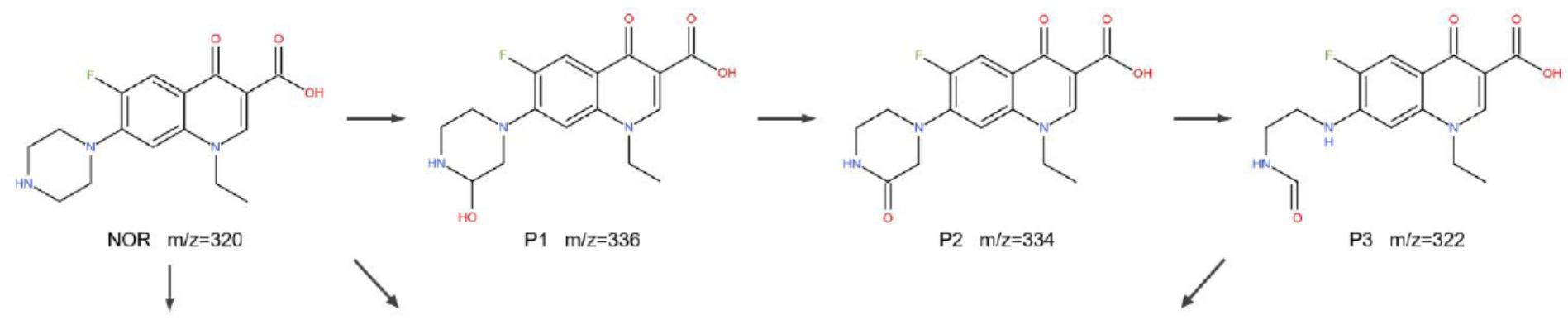

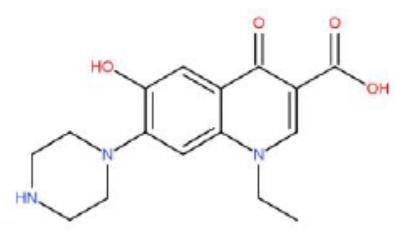

P7 $\mathrm{m} / \mathrm{z}=318$

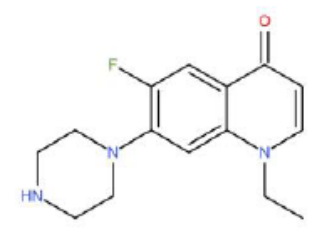

P5 $\mathrm{m} / \mathrm{z}=\mathbf{2 7 6}$
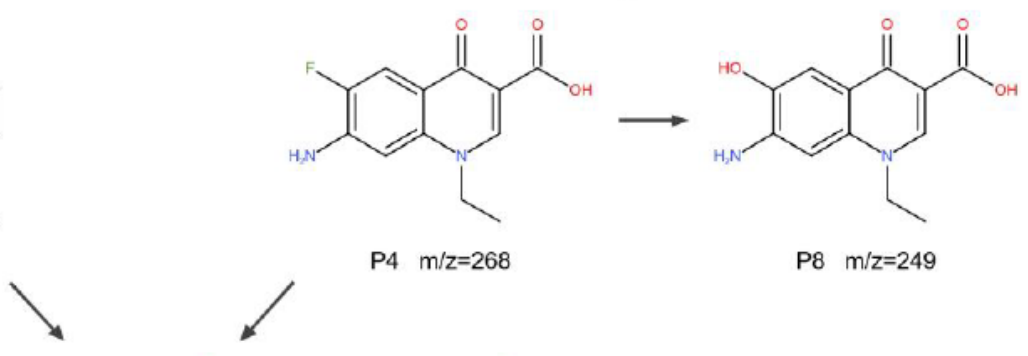

P4 $m / z=268$

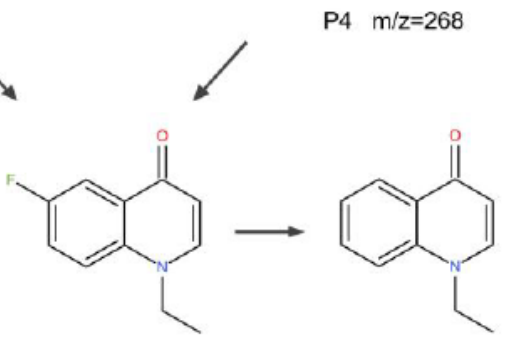

$\mathrm{P} 9 \mathrm{~m} / \mathrm{z}=212$

\section{Figure 8}

Possible pathways of photocatalytic degradation of norfloxacin by MMIP 


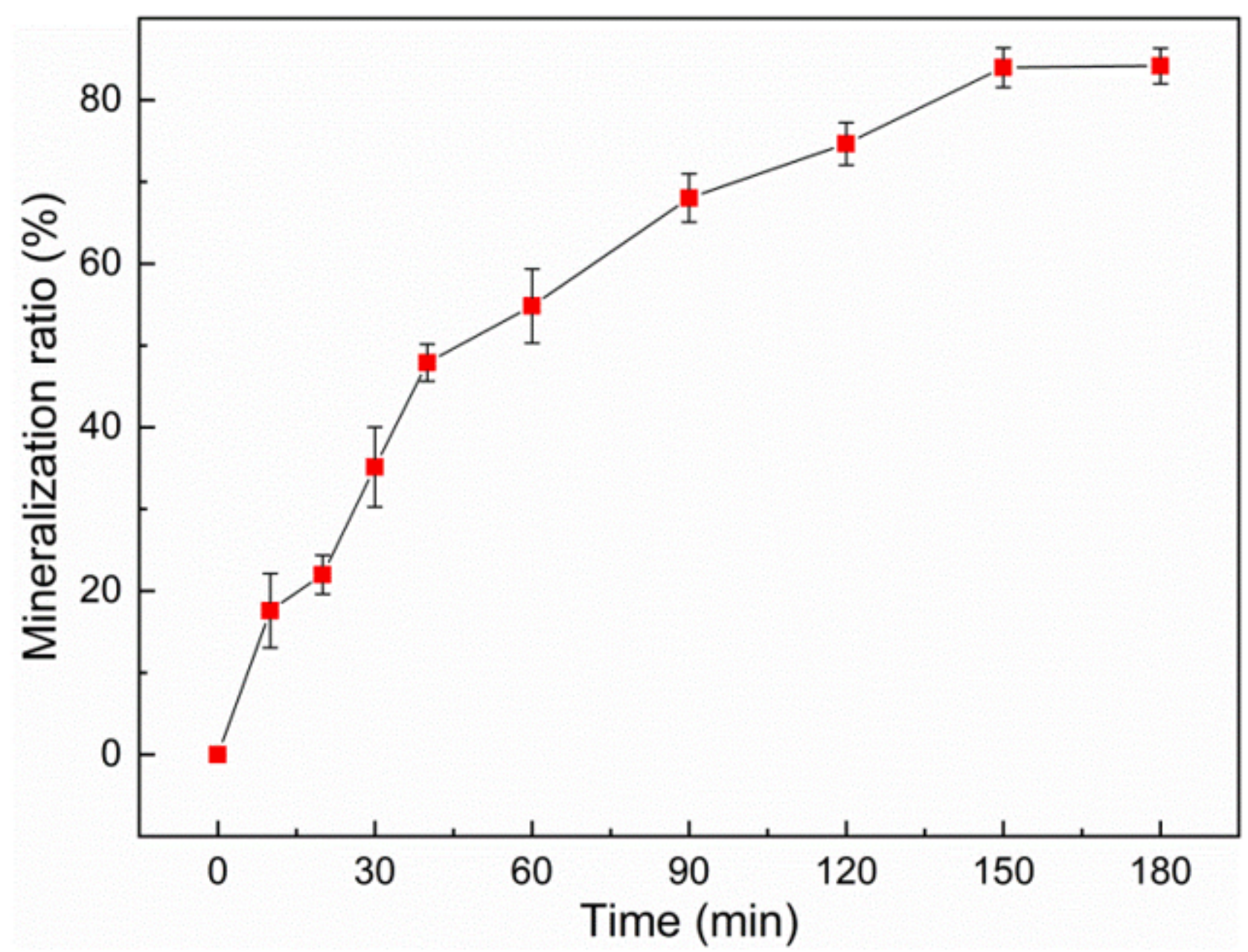

Figure 9

Mineralization ratio of photocatalytic degradation of norfloxacin by MMIP 


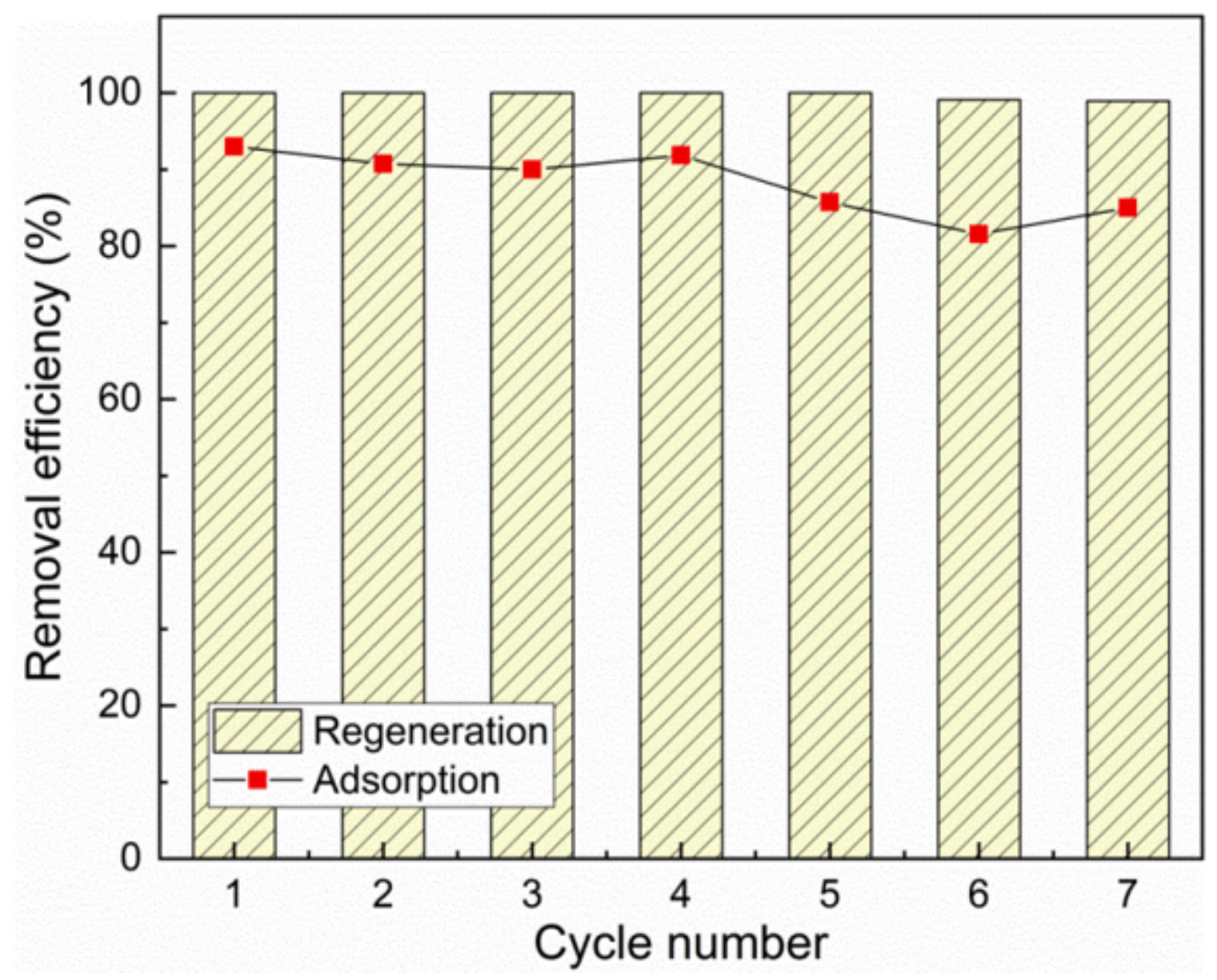

Figure 10

In-situ regeneration and recycling performance of MMIP 


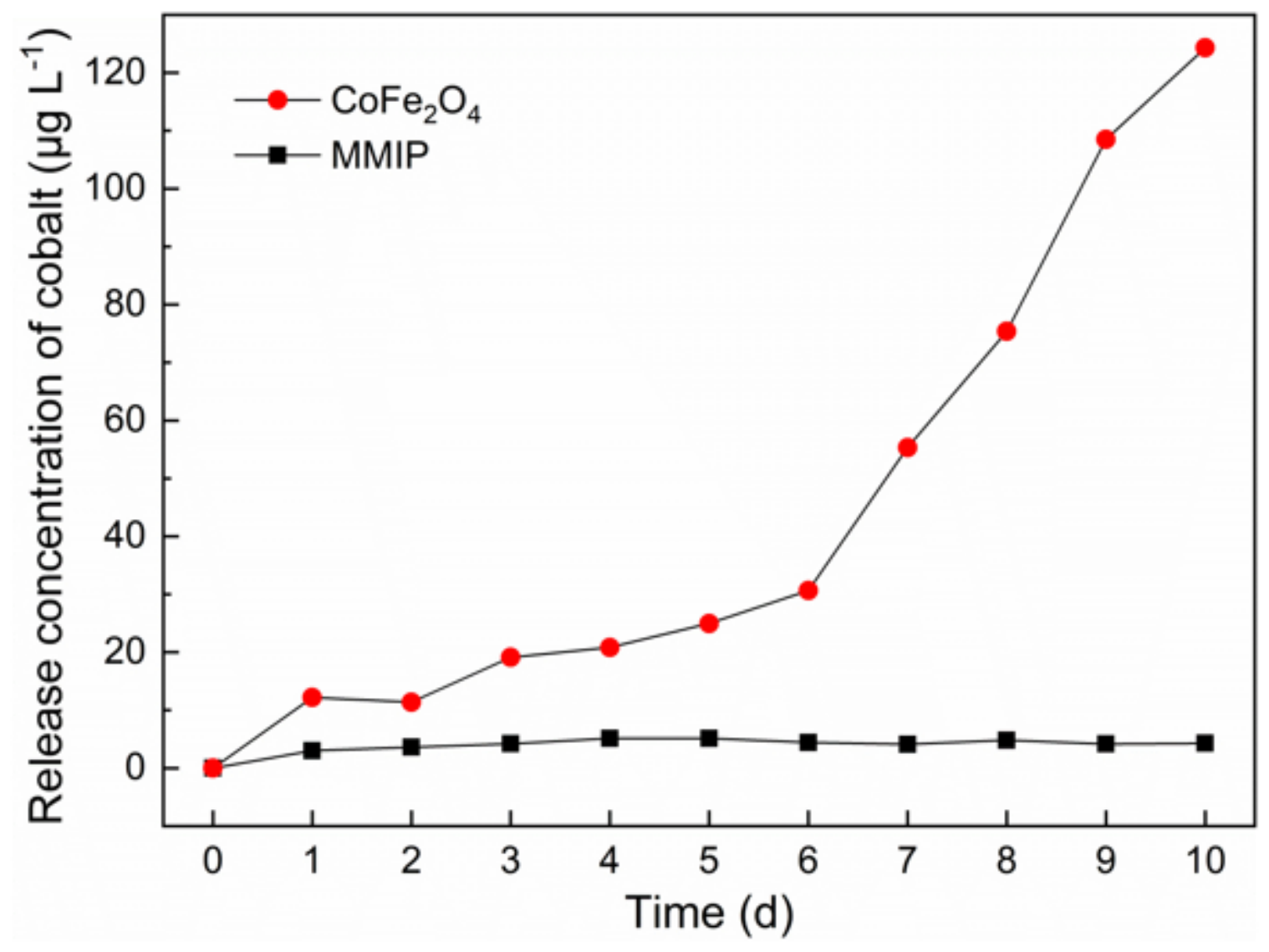

Figure 11

Concentration of cobalt released by $\mathrm{CoFe} 2 \mathrm{O} 4$ and MMIP in aqueous solution 